\title{
USINA HIDRELÉTRICA DE BELO MONTE: UMA VISÃO CRÍTICA DA PRINCIPAL FONTE DE ENERGIA DO PAÍS
}

\section{BELO MONTE HYDROELECTRIC POWER PLANTS: A CRITICAL VISION OF THE PRINCIPAL COUNTRY POWER SOURCE}

\author{
Ródney Silvério Costa Júnior; Ester Alcântara de Carvalho²; Rafael Marcal ${ }^{3}$ \\ ${ }^{1}$ Unisalesiano, Estudante de Engenharia Civil, Araçatuba, SP \\ E-mail: juniorcivil.sale@hotmail.com \\ ${ }^{2}$ UNIP, Estudante de Engenharia Civil, São José do Rio Preto, SP \\ E-mail: esteralcantaracarvalho15@gmail.com \\ ${ }^{3}$ Unip , Professor e Mestre , Araçatuba, SP \\ E-mail: rafael g1@hotmail.com
}

RESUMO - Energia renovável, energia alternativa ou energia limpa são os três possíveis nomes para qualquer energia obtida por meio de fontes renováveis. Tendo em vista, tais fontes, o foco desse artigo será analisar a energia hidrelétrica, mais especificamente, a usina de Belo Monte e as polêmicas em torno dela, que tiveram início antes mesmo da sua construção. A usina que é cem por cento brasileira, está instalada no interior do Pará, no rio Xingu. O debate que já se prolonga há anos, são os graves impactos negativos que ela causa, tanto sociais, quanto ambientais. Tendo em vista este contexto, este artigo insere-se como uma crítica sobre os tais impactos, que podem causar danos irreparáveis, e também uma explicitação do dilema resultante entre o progresso e a conservação do meio ambiente. Concluí-se que é necessário encontrar um equilíbrio entre essas duas vertentes essenciais, para possibilitar, de fato, uma evolução que não cause um desastre ambiental. Palavras-chave: geração hidrelétrica; energia; meio ambiente.

ABSTRACT - Renewable energy, alternative energy or clean energy are the three possible names for any energy obtained by renewable sources. Knowing this sources, the focus of this article will be analyze hydroelectric energy, more specifically, the plant of Belo Monte and the controversies around it, that appeared even before its construction. The plant, which is one hundred percent Brazilian, is installed in the interior of Pará, on the Xingu River. The debate that has been going on for years are the serious and negatives impacts that it causes, both social and environmental. Knowing this context, this article it is a criticism about this impacts, which is irreplaceable effect, and being an exploitation of the dilemma between the pree and the conservation of the environment. We conclude that it is necessary to find a break-even point between the two essential strands, to actually enable an evolution that does not cause an environmental disaster.

Keywords: hydroelectric generation; energy; environment. 


\section{INTRODUÇÃO}

$O$ consumo de energia baseada em fontes fósseis, vem gerando muita emissão de gases poluentes, e gases de efeito estufa, como o dióxido de carbono, tornando-a uma fonte inviável, uma vez que coloca em risco a preservação do meio ambiente. Pensando nisso, surgiram novas maneiras de extrair energias, fontes de energias renováveis, que oferecem mais vantagens, dentre elas, serem mais limpas e respeitarem a natureza. Desta maneira, a energia hidrelétrica, entra em pauta, sendo uma das possíveis fontes de energia provenientes de recursos naturais.

O funcionamento da fonte de energia mencionada (hidrelétrica), de um modo bem simplificado, pode ser entendido assim: as hidrelétricas funcionam através de grandes turbinas que giram devido à pressão/força das águas. A água passa por tubos que são interligados às turbinas, fazendo-as girar. Cada turbina é acoplada a um equipamento chamado gerador, formando assim, a unidade geradora que faz a transformação da energia mecânica, do movimento das pás da turbina, em energia elétrica. Pode-se observar, a exemplificação na figura 1 a seguir:

Figura 1. Funcionamento de uma usina hidrelétrica

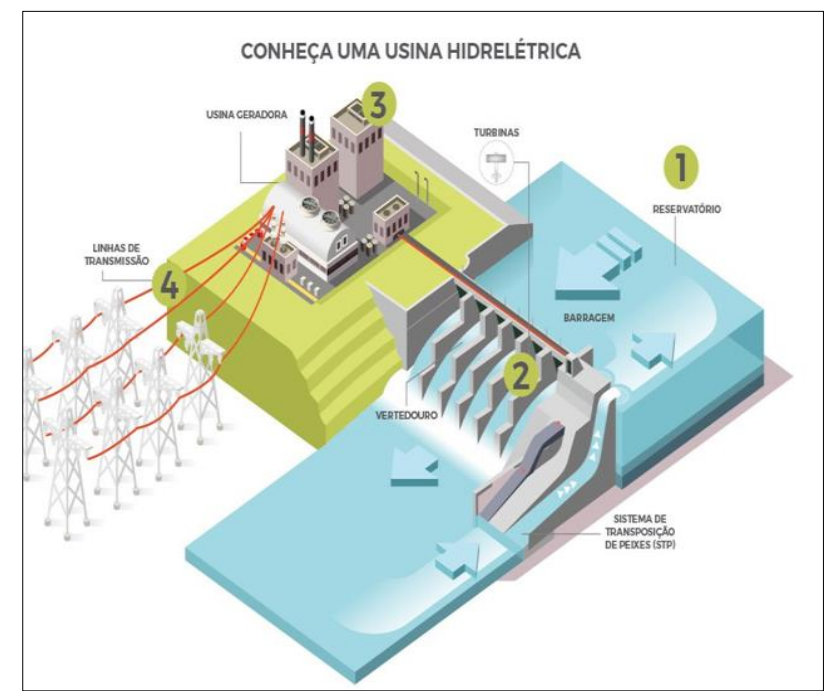

Fonte: (Aliança Energia, 2017).

Tendo em vista essa ideia de fontes de energia renováveis, o Brasil se destaca dos demais países, por ser um país que possui capacidade de ingressar nesse novo conceito e também por abranger uma abundante região de água, como de outros recursos naturais. Os projetos hidrelétricos, no caso brasileiro, assumem então, uma especial importância porque "a hidroeletricidade é a base do suprimento energético do Brasil" (MÜLLER, 1995). Inicia-se, portanto, a exploração e construção desses novos modelos viáveis ao nosso país, mais diretamente, o hidráulico. Porém, começam a surgir novas preocupações, como é exemplificado abaixo:

Os empreendimentos hidrelétricos inserem-se dentro do interesse coletivo de uma sociedade por elevar, através da oferta de energia, a qualidade de vida da população. No entanto, além dos benefícios energéticos devem ser considerados os efeitos prejudiciais do empreendimento.

(Wanderley Lemgruber, 2000, p. 9).

Uma definição da proporção agravante que foi esse conflito, será mostrado abaixo:

O conflito em torno da construção da Usina Hidrelétrica de Belo Monte é um conflito ambiental justamente no sentido em que é um conflito no qual, mais do que disputas materiais $\mathrm{e}$ simbólicas pelo uso de recursos, estão em jogo experiências da relação sociedade-natureza atravessadas pela noção de desenvolvimento. 0 conflito se demonstra, assim, uma disputa cosmopolítica - ou seja, expressa perspectivas ontológicas concorrentes, que se colocam em choque face ao projeto moderno de desenvolvimento. (Lorena Cândido, 2013, pag. 2).

Localizada na bacia do Rio Xingu, próximo ao município de Altamira, no norte do Pará, a Usina Hidrelétrica de Belo Monte que ostenta o título de uma das construções mais caras do país, orçada inicialmente em $\mathrm{R} \$ 16$ bilhões, leiloada 
por $\mathrm{R} \$ 19$ bilhões e financiada por $\mathrm{R} \$ 28$ bilhões. Apesar de ter sido inaugurada em 2016, a pretensão de construí-la não é de agora, a usina de Belo Monte é um projeto antigo, o qual começou a ser desenhado em 1975, e desde então, é marcado por vários protestos que tentam barrar a sua construção; protestos esses, feitos desde a própria população afetada até ambientalistas que defendem a preservação da biodiversidade, do meio ambiente, da qualidade de vida da população ao redor, entre outros fatores.

Certo é que os impactos causados por essa usina (desde a época de sua construção, até os dias atuais) são inúmeros, diversos e perceptíveis a quem quer que se atentar ao caso.

Será abordado nesse artigo da construção da usina hidrelétrica de Belo Monte, e mostrar o lado crítico dessa fonte renovável que o Brasil, apostou como sendo a principal geradora de energia do país, provendo dela a porcentagem de $70 \%$ da energia elétrica total do país. Será demonstrado a profundidade dessa construção, os conflitos que ela desencadeou.

\section{METODOLOGIA}

Foram feitas várias pesquisas sobre o tema, quanto na parte jornalística, para obter informações e dados concretos, fornecidos pelo site do governo, ou por algumas pesquisas, evidenciando os resultados encontrados, tanto na parte científica, para ter conhecimento de diversas críticas e opiniões sobre o assunto.

Analisando relatos feitos pelos moradores ao redor da usina, por meio de entrevistas, para conseguir ter acesso a detalhes que constam o lado dessas pessoas que não possuem visibilidade.

Através de sites que mostram como por exemplo, dados de índice de violência, foi comparado os dados, anterior e após a construção da usina, sendo observado então, o aumento do mesmo.

\section{RESULTADOS}

Mostra-se no artigo, todos os impactos que a população alega que os afetaram, como por exemplo, o leito original do rio, que foi desviado, prejudicando agricultores e a população local, através da interrupção do transporte fluvial, que possibilita aos moradores, atendimento médico e odontológico, comercializações, como a venda de peixes (que também foi prejudicada pela diminuição da vazão do rio Xingu) e castanhas, e irem à escola, no caso dos estudantes.

Para a construção da usina, o desmatamento obteve uma intensificação extrema, além da usina ter atraído mão de obra, ocasionando, a ocupação desordenada do território, o qual não estava preparado para tal demanda; as pessoas começaram a construir moradia em locais perigosos; e os serviços de saúde, que já eram precários, pioraram, por não haver recursos suficientes para agregar a nova população. $O$ aumento da densidade demográfica foi desproporcional a eficácia do governo local. Uma prova disso, foi o aumento da violência na cidade de Altamira, que é o município mais próximo da usina.

Figura 2. Mapa de cidades mais violentas no país

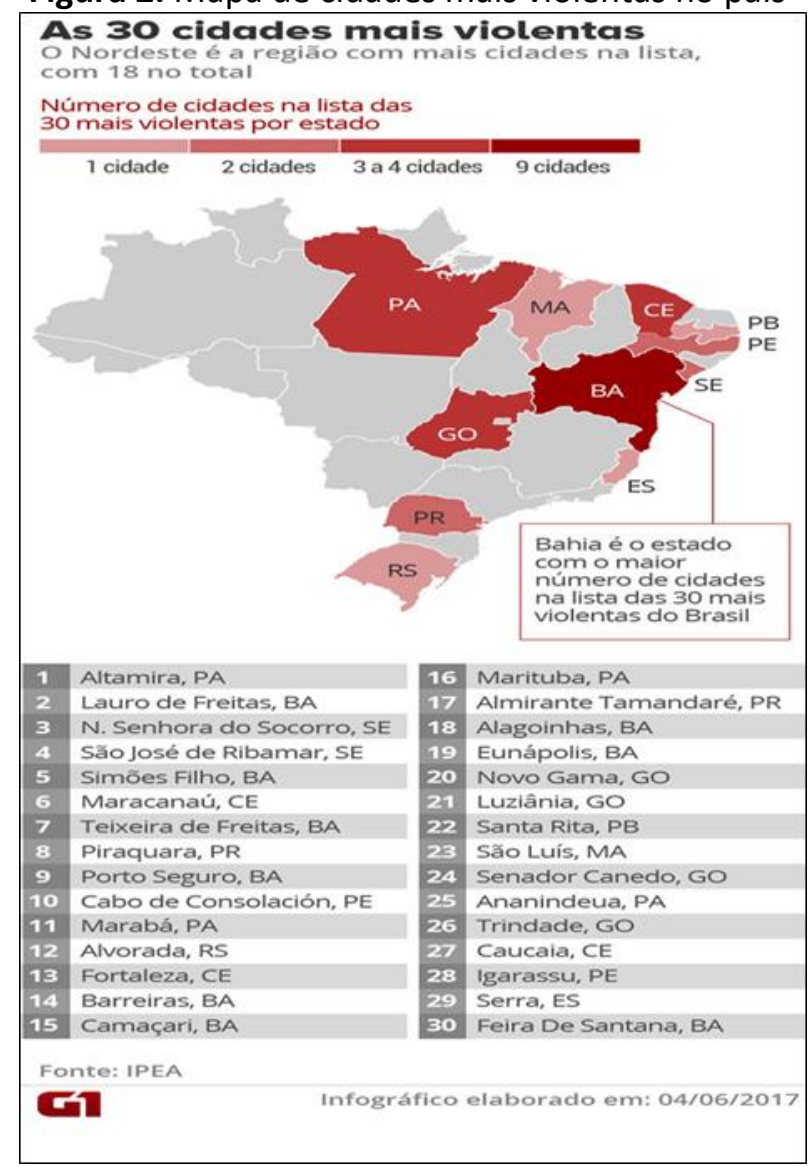

Fonte: (G1 Globo, 2017).

Outro aspecto se deve ao fato da construção da usina não ter reservatório de água, logo depende, da presença e quantidade de chuvas, desta forma, sua capacidade tornou-se dependente de condições climáticas imprevisíveis. 
Além disso, outro resultado negativo, apresentado, foi que com a instalação da infraestrutura da obra afetou a flora e a fauna local, causando uma perda irreversível de centenas de espécies. Levando estes dados em consideração, a viabilidade econômica desta construção se torna contraditória.

Todos esses fatores que na época da construção da usina já preocupavam a população, atualmente tem acontecido outras polêmicas envolvendo a usina. Como, por exemplo, alega a empresa Norte Energia, que a hidrelétrica de Belo Monte poderá enfrentar anos consecutivos de perdas milionárias de faturamento devido à falta de capacidade do sistema de transmissão para escoar toda a produção da usina.

Recentemente, o órgão Operador Nacional do Sistema Elétrico (ONS) informou um fato, por meio da revista Época Negócios, que afetou todo o Brasil, uma falha na linha de transmissão que conecta a hidrelétrica de Belo Monte ao sistema elétrico, gerou um blecaute de grandes proporções no Brasil, com maiores impactos no Norte e no Nordeste, mas com desligamentos registrados em todas as regiões do país. 0 problema levou ao desligamento de $22,5 \%$ da carga de energia do sistema brasileiro.

Figura 3. Bloqueios feitos na região

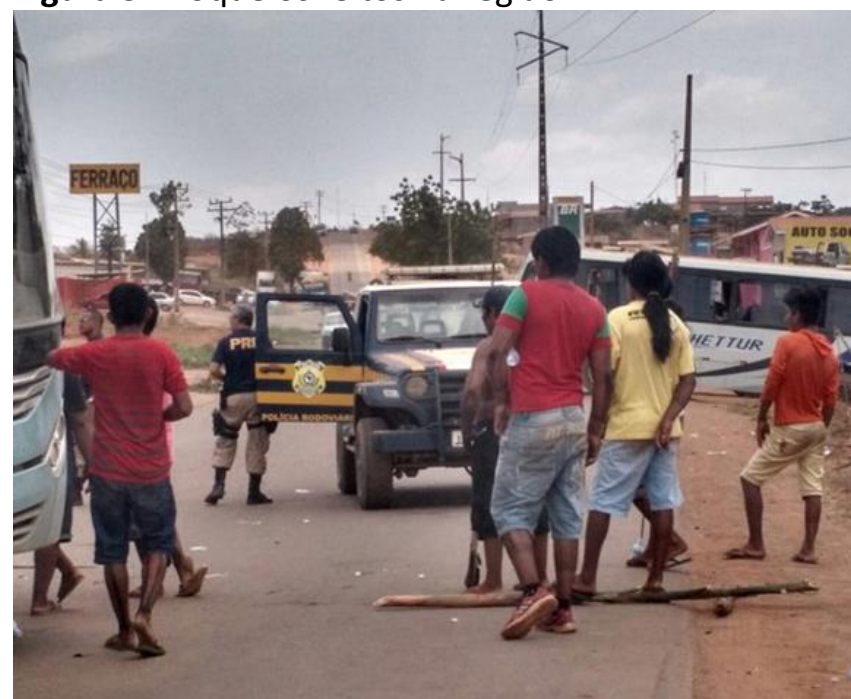

Fonte: (G1 Globo, 2014).

Interessa destacar que, somando-se as ações contra a construção da usina hidrelétrica movida por outras entidades, como Defensoria Pública do estado do Pará e organizações não governamentais, o número de processos no judiciário contrários à Belo Monte totaliza 57 ações. Para uma sistematização atualizada das ações movidas pelo MPF/PA, consultar
http://www.prpa.mpf.mp.br/news/2013/arquivos/Ta bela_de_acompanhamento_atualizada_23-10-13.pdf.

Em contrapartida, algumas melhoras foram apresentadas, conforme os dados que o Brasil Gov (2016) mostra, como o investimento de $14 \%$ do orçamento da construção da usina, em melhorias no desenvolvimento de 12 municípios ao redor da usina.

Foi instalado, algo primordial para o mínimo de qualidade de vida e saúde que uma cidade exige, saneamento básico.

$\mathrm{Na}$ parte de educação, foram construídas algumas escolas na região.

Foram construídos novos bairros dentro da cidade, para afastar 30 mil moradores, das regiões de riscos.

A empresa responsável pela usina, Norte Energia, plantou 26 mil hectares com espécies nativas, para preservar as florestas e a biodiversidade, uma vez que a área da usina foi afetada com o desmatamento.

$\mathrm{Na}$ área de empregos, a população foi beneficiada, com cerca de 20 mil empregos diretos e 40 mil empregos indiretos na região.

\section{DISCUSSÃO}

Através dos resultados pode-se constatar algumas melhorias para a população que mora ao redor da usina, conforme mostra, na segunda coluna, após a figura 3, na página 6 do artigo. É o mínimo de condição de vida que qualquer comunidade precisa, e é responsabilidade do governo oferecer essas condições. Essas pessoas deveriam ter esse tratamento digno, não só pela construção da usina, mas pelo cumprimento de tudo que os direitos dos cidadãos, garante, conforme Carneiro:

O Princípio da Dignidade visa garantir a proteção integral dos elementos da personalidade do homem, indispensáveis para que este tenha uma existência digna, refletindo assim a consagração dos Direitos Humanos relacionados. Tal proteção deve ser indistintamente oferecida a todos os homens, independentemente de nacionalidade, raça, religião, filosofia etc. Para tanto, o homem nem precisa ter consciência dos direitos que possui; a igualdade na destinação e aplicação dos princípios deve ser isonômica a todos os indivíduos humanos. 
(Maurício Carneiro, 2014 pag.15).

Mesmo com tais melhorias, a população segue insatisfeita, por serem mais significativo os impactos negativos do que os positivos. Pode-se observar que mesmo se tratando de uma fonte renovável, e que muitos julgam ser limpa, a usina, prejudicou, em uma proporção menor do que as energias não-renováveis, porém não ficou isenta do desmatamento do meio ambiente, e de colocar em risco a biodiversidade, como tantas outras coisas.

Um caso explicito da ameaça de Belo Monte a biodiversidade existente no Rio Xingu:

A bacia do Amazonas
concentra a maior
biodiversidade aquática do planeta, com $16 \%$ das espécies de peixe de água doce do planeta. Pouco menos que a metade das 2.411 espécies descritas são endêmicas (é aquela espécie animal ou vegetal que ocorre somente em uma determinada área ou região geográfica), ou seja, não existem em nenhum outro lugar. O Rio Xingu é o maior fornecedor de águas claras. É nele que fica a Volta Grande do Xingu, uma região especial que, por conta de sua complexidade, conta com um alto nível de biodiversidade e endemismo, como o pulso de enchente e vazante será profundamente alterado, o nível da água não será suficiente para manter a nutrição da vegetação nas ilhas, nem para que a fauna aquática tenha acesso às áreas inundáveis, prejudicando sua reprodução. (FRITZGERALD, 2016, pag.2).

Uma das espécies ameaçadas de extinção vive nas fendas das pedras nas corredeiras do Xingu: o Acari Zebra (Hypancistrus zebra), conhecido como "Zebrinha". Os Juruna, povo indígena, que são mergulhadores e conhecedores do rio perceberam a diminuição do número de zebrinhas e se preocuparam com o desaparecimento dessa espécie que só vive nas correntezas, habitat particularmente vulnerável às alterações hidrológicas, causadas pela usina.
Abaixo pode-se ver a espécie descrita, como mostra a figura 4:

Figura 4. Peixe zebrinha

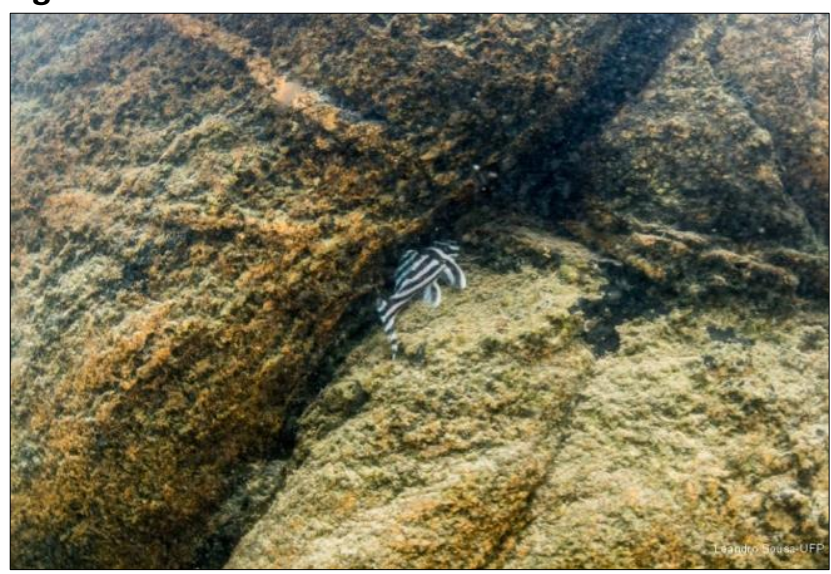

Fonte: (Instituto Socioambiental (ISA), 2018).

Conforme foi mostrado, os impactos atingiram e continuam atingindo não apenas as pessoas que vivem ao redor, mas também a fauna e a flora.

É preciso que as minorias ganhem espaço na mídia, para mostrarem à toda população nacional, que o patrimônio brasileiro vem sendo destruído aos poucos, e notificar os riscos que a natureza sofre, para que todos possam estar cientes e tomarem as devidas providências.

Contextualizando com todos esses fatores negativos que foram mostrados, uma definição de Belo Monte segundo o professor de pós-graduação em Energia do Instituto de Eletrotécnica e Energia da USP, mostra, o quão caótica a situação se tornou, sendo Belo Monte uma representação simbólica da possibilidade de transformar todo o território amazônico em um grande conjunto de jazidas de megawatts (BERMANN,2010).

\section{CONSIDERAÇÕES FINAIS}

Nesse duelo de gigantes, a empresa Norte energia e a população afetada, cada lado defende seu ponto de vista. Para a Norte Energia, a construção de Belo Monte colocou aquela região do Pará no mapa de investimentos. Segundo Luciana Soares, gerente do Meio Socioeconômico da empresa, (2017) "Somos partícipes de um processo de transformação dessa região, um novo olhar para essa região de Amazônia, um olhar que vise um legado de sustentabilidade".

Já as organizações não governamentais da região discordam fortemente, Marcelo Salazar, (2017), rebate, "Na observação do Instituto Socioambiental, quase $100 \%$ dos grupos dos impactados estão numa situação muito pior do que 
viviam anteriormente". Em contrapartida, líderes indígenas possuem outro ponto de vista conforme explicita-se abaixo:

Nosso povo precisa sobreviver, nosso povo precisa desenvolvimento sustentável, aprender a produzir e a cuidar daquilo que é nosso. Estamos lutando não contra o desenvolvimento, mas pelo nosso planeta, pelo mundo. (Liderança indígena Juruna, Volta Grande do Xingu, junho/2011).

É necessário que essas minorias ganhem mais espaço na mídia, visibilidade, para mostrarem à toda população nacional, que o patrimônio brasileiro vem sendo destruído aos poucos, e notificar os riscos que a natureza sofre, para que todos possam estar cientes e tomarem as devidas providências.

Conclui-se que mesmo sendo uma fonte de energia renovável, a energia hidrelétrica para ser viabilizada, provoca diversas consequências socioambientais, necessitando-se de cuidado no remanejamento de fauna, flora e comunidades ribeirinhas. Portanto, por ser um país em sua maioria abastecido por esta fonte de energia, é necessário este tipo de análise crítica da situação, em busca de melhorias e alternativas de mitigação dos problemas causados pela inserção de usinas, a fim de encontrar um equilíbrio entre e natureza e as necessidades do homem.

\section{REFERÊNCIAS}

CARNEIRO, Maurício. A Usina Hidrelétrica de Belo Monte e suas implicações quanto aos Direitos Fundamentais da população que vive em torno do projeto. Jus Brasil, Salvador - BA, dez./ago. 2018. Disponível em: <https://mauriciocarneiro.jusbrasil.com.br/artigos/11 3959939/a-usina-hidreletrica-de-belo-monte-e-suasimplicacoes-quanto-aos-direitos-fundamentais-dapopulacao-que-vive-em-torno-do-projeto>. Acesso em: 08 ago. 2018.

CARTA CAPITAL. Após um ano de funcionamento, Belo Monte segue envolta em polêmicas. Disponível em:

<https://www.cartacapital.com.br/sociedade/aposum-ano-de-funcionamentobelo-monte-segueenvolta-em-polemicas>. Acesso em: 05 ago. 2018.
EPOCA NEGOCIOS. Falha em linha de Belo Monte gera blecaute no Norte e Nordeste e afeta outras regiões. Disponível em: $<$ https://epocanegocios.globo.com/Brasil/noticia/201 8/03/epoca-negocios-blecaute-corta-225-da-cargano-brasil-norte-e-nordeste-tem-maior-impacto-dizons.html>. Acesso em: 21 ago. 2018.

EXAME ABRIL. Usina de belo monte alega perda milionária por restrição em sistema. Disponível em: $<\quad$ https://exame.abril.com.br/economia/usinade-belo-monte-alega-perdamilionaria-por-restricaoem-sistema/>. Acesso em: 04 ago. 2018.

FLEURY, Lorena Cândido. ARTIGOS ORIGINAIS A construção da Usina Hidrelétrica de Belo Monte: conflito ambiental e o dilema do desenvolvimento. SciELO, São Paulo, v. 16, n. 4, out. 2018. Disponível em:

<http://www.scielo.br/scielo.php?script=sci_arttext\& pid=S1414-753X2013000400009>. Acesso em: 03 ago. 2018.

FITZGERALD, D. B. et al. Diversidade e estrutura das comunidades de peixes que habitam as corredeiras do rio xingu: implicações para a conservação diante do desenvolvimento de uma hidrelétrica de grande escala. Biological conservation, Cidade, p. 01-15, jul./set. $2018 . \quad$ Disponível em: <https://www.socioambiental.org/sites/blog.socioam biental.org/files/nsa/arquivos/diversidade_e_estrutu ra_das_comunidades_de_peixes_que_habitam_as_c orredeiras_do_rio_xingu_implicacoes_para_a_conser vacao_diante_do_desenvolvimento_de_uma_hidrele trica_de_grande_escala_2.pdf $>$.Acesso em: 24 ago. 2018.

G1 GLOBO. Atingidos pela obra de Belo Monte bloqueiam a BR-230, de acesso à usina. Disponível em:

https://g1.globo.com/pa/para/noticia/2018/07/30/at ingidos-pela-obra-de-belo-monte-bloqueiam-arodovia-br-230-de-acesso-a-usina.ghtml >. Acesso em: 29 ago. 2018.

G1 GLOBO. Maracanaú, Fortaleza e Caucaia estão entre as $\mathbf{3 0}$ cidades mais violentas do Brasil, diz Ipea. Disponível em: <https://g1.globo.com/ceara/noticia/maracanaufortaleza-e-caucaia-estao-entre-as-30-cidades-maisviolentas-do-brasil-diz-ipea.ghtml>. Acesso em: 03 set. 2018. 
GUIA DA CARREIA. Usina de Belo Monte: energia ou impacto ambiental?. Disponível em: <https://www.guiadacarreira.com.br/educacao/usina -hidreletrica-belo-monte/>. Acesso em: 20 ago. 2018.

PENSAMENTO VERDE. A construção da Usina de Belo Monte e seus impactos ambientais. Disponível em: <https://www.pensamentoverde.com.br/meioambiente/a-construcao-dausina-de-belo-monte-eseus-impactos-ambientais/>. Acesso em: 20 ago. 2018.

SOCIO AMBIENTAL. Belo Monte coloca biodiversidade do Xingu em risco. Disponível em: $<$ https://www.socioambiental.org/pt-br/noticiassocioambientais/belo-monte-coloca-biodiversidadedo-xingu-em-risco>. Acesso em: 04 set. 2018.

SOUSA, Wanderley Lemgruber De. IMPACTO AMBIENTAL DE HIDRELÉTRICAS: UMA ANÁLISE COMPARATIVA DE DUAS ABORDAGENS. Tese (Pósgraduação de engenharia) - UFRJ. Rio de Janeiro, v. VII, n. 154, p. 1-160, ago. 20. Disponível em: <http://ppe.ufrj.br/ppe/production/tesis/wlemgrube r.pdf>. Acesso em: 20 ago. 2018.

VIO MUNDO. Bermann: “A energia hidrelétrica não é limpa, nem barata". Disponível em: <https://www.viomundo.com.br/entrevistas/berman n-a-energia-hidreletricanao-e-limpa-nem-

barata.html>. Acesso em: 03 set. 2010. 